\title{
The Ethics Pyramid: Making Ethics Unavoidable in the Public Relations Process
}

\author{
Elspeth Tilley \\ Department of Communication and Journalism \\ Massey University
}

\begin{abstract}
$\square$ To move from the realm of good intent to verifiable practice, ethics needs to be approached in the same way as any other desired outcome of the public relations process: that is, operationalized and evaluated at each stage of a public relations campaign. A pyramid model — the "ethics pyramid"—is useful for incorporating ethical reflection and evaluation processes into the standard structure of a typical public relations plan. Practitioners can use it to integrate and manage ethical intent, means, and ends, by setting ethics objectives, considering the ethics of each campaign tactic, and reporting whether ethical outcomes have been attained.
\end{abstract}

\section{The Need for Practical Ethics Tools}

Few public relations (PR) scholars or practitioners would dispute Bowen's (2004) claim that "public relations is a field fraught with ethical dilemmas" (p. 65). There is widespread awareness of ethics as a key issue and growing discussion by academics and practitioners about how to approach professional ethics. Yet, as Bowen also argued, "too few works on public relations ethics have been published to serve as guidelines to practitioners" (p. 65). Scholarly work, as is the nature of healthy academic debate, offers diverse theoretical frameworks (Baker, 1997, 2002; Bowen, 2004; Fitzpatrick \& Gauthier, 2001; K. A. Leeper, 1996; R. V. Leeper, 1996; Marsh, 2001; Martinson, 2000, 2004; Pearson, 1989, to name a few). Academic work often contradicts or critiques previous scholarship: For example, Grunig (2001), and Cancel, Mitrook, and Cameron (1999) debated whether practitioners can be inherently ethical by using two-way symmetrical communication. Practitioners looking for consistency or consensus on the single "best" or "easiest" way to be ethical will not readily find it in the academic literature.

One of the key reasons for the lack of academic consensus, however, is that there is no "one right way" to be ethical. As the exploration below illus- 
trates, each of the main ethical philosophies has both strengths and limitations under different circumstances. None offers a "cure-all" ethics policy. Rather, the most comprehensive approach is one that incorporates multiple ethical aspects, not only encompassing aspirational virtues for practitioners, but also setting some reasonable prohibitions or limits on behavior as well as considering the overall goals of any given campaign. If practitioners are expected to administer a variety of ethics approaches, however, they need a system to manage the overall process. Furthermore, they need a system that integrates with, rather than adds new stages to, the plethora of activities already undertaken in the daily practice of public relations.

\section{Evaluation: Once Is Never Enough}

In 1984, Dozier suggested PR evaluation requires clusters of technologies rather than single-step assessments, and continuous rather than afterthe-thought application. Subsequently, several useful models have streamlined and mapped the evaluation process, listing evaluation technique choices and corralling them into practical and sequential groupings that follow a typical campaign schedule. Fleisher and Mahaffy (1997), for example, adapted a balanced scorecard approach, recommending practitioners develop "a set of audience/client/stakeholder, financial, improvement, and operational/process performance measures that reflect progress against a plan" (p. 117). Their system measures and tracks PR activity, but is "more than just a measurement system" (p. 117). It also provides an integrated, sequential process that helps practitioners "clarify, communicate and manage" (p. 117) their organization's overall public relations strategy.

Macnamara's (2002) pyramid model likewise proposed continuous, sequential evaluation. He split campaigns into three stages-inputs, outputs, and outcomes, corresponding roughly to planning; writing, communicating, or acting; and evaluation phases-and suggested appropriate evaluation methods for each. The key strength of both Macnamara's and Fleisher and Mahaffy's (1997) models is that they manage evaluation simultaneously at both micro- and macrolevels, offering specific techniques to assess particular activities or tactics but also ensuring an overarching system to evaluate the campaign as a whole.

The benefits of sequential, multistage modeling also apply to ethics assessment. 
Although models such as these provide neat, easy-to-follow evaluation instructions for students and practitioners (and Macnamara's, 2002, model is particularly useful pedagogically because of its clear graphic representation of the steps involved), they only evaluate PR's operational and strategic effectiveness, usually in terms of outcomes for the client organization and its stakeholder groups. Neither model specifically addresses ethics. Yet the benefits of sequential, multistage modeling also apply to ethics assessment. A step-by-step model integrating ethics with existing campaign activity would enable PR practitioners to measure, clarify, communicate, and manage an ethical compliance strategy at micro- and macrolevels, transforming ethics from an abstract concern into a standard reporting line, alongside financial, behavioral, attitudinal, sales, inquiry levels, or any other measurable outcomes in typical public relations campaigns.

The ethics pyramid applies multistage, objective-based modeling to professional ethics. Macnamara's (2002) pyramid design for PR research and evaluation reflected his concern (shared by many others, e.g., Childers Hon, 1998; Grunig \& Grunig, 2001) that PR evaluation was traditionally too tactics-focused, concentrating on measuring individual outputs, e.g., counting clippings. His three-step pyramid sandwiches output measurement between construction and measurement of objectives for the whole campaign, to ensure evaluation always measures both tactics and strategy. Where ethics is concerned, in practice and in the academic literature, the emphasis has tended to be "big picture," with most attention on general ethical intent or overall ethical outcomes. The widely used Potter Box, for example (McElreath, 1997), focuses on identifying values and choosing loyalties, and can be used to make decisions without assessing the ethics of means. A three-step system incorporating tactical ethics within strategic ethics ensures balance. If the highest ethical standard involves not only ethical intent but also ethical means and ends, a three-stage model ensures all three (intent, means, and ends) are considered. As a basic structure and visual representation, Macnamara's design provided a useful starting point for developing an ethics management system.

Another useful aspect of Macnamara's (2002) design is his "menu" feature, in which he offered a list of evaluation techniques, grouped according to those likely to be most useful at each campaign stage. Ethics likewise needs to be addressed at many points during the campaign, using different approaches. As the discussion later indicates, no one ethics tool or approach can predict or resolve every potential ethical dilemma in any given campaign, and a list of interchangeable techniques can give practitioners the flexibility to address disparate circumstances while still retaining an overall ethical management structure. 


\section{Evaluating Ethics: The Need for a Multimethod Approach}

Each of the different theoretical approaches proposed for PR ethics has admirers and detractors. It is not possible to overview all these debates here, but some of the more common approaches and tools are briefly discussed below, roughly grouped according to three key "schools of thought": virtue ethics, deontology, and consequentialism. Each of these approaches has strengths and weaknesses, which lead to the pconclusion that a combination of approaches provides the best possible ethical coverage.

As each approach is discussed, practical ways of incorporating it into a PR campaign, using the pyramid, are suggested. These practical suggestions are then collated in a "how to" section that gives generic instructions for using the pyramid.

\section{Virtue Ethics}

Virtue ethics involves fostering a strong internal moral compass to guide right action. Martinson (2000) suggested that two Aristotelian virtue ethics principles are helpful to PR practitioners. The first is to develop ethical judgement by "stimulating the moral imagination ... to recognize ethical issues" ( $\mathrm{p}$. 19). This could be achieved in a campaign through ethics brainstorming sessions or ethical reflection times where individuals considered ethical implications and reported back to the team, or through discussions with an independent ethics consultant, who could highlight potential ethical issues in the upcoming campaign and stimulate debate on appropriate approaches.

Martinson's (2000) second recommendation is the Aristotelian virtue principle to aim for reasonable behavior by considering the ethical mean, which Harrison (2004) described as "one point of a triangle with excess and deficit at the other points" (p. 1). Harrison recommended practitioners implement the mean by asking "how ought a person of good character, a person of integrity, feel and act in this situation?" (p. 2), while Harrison and Galloway (2005) recommended asking "What is it that PR practitioners do of which we can be (or are) proud?" (p. 2). Other simple tools for ascertaining reasonable behavior might be the front page or publicity test (Would you feel comfortable with the planning decisions you are making being on the front page of the newspaper?) and the mum test (Would you feel comfortable that your mother-or any significant other whose values you admire and whose approval you desire-would applaud your planned behavior in this campaign?).

The pyramid approach allows practitioners to select those or any other virtue tests that accord with their values, and set relevant virtue objectives 
to be revisited and tested at the end of the campaign. If virtue questions are built into campaign planning by converting them from rhetorical questions into stated objectives relating to specific stakeholders, virtue ethics becomes a formative step in the PR process, rather than a reactive process once problems arise.

To explain this in operational terms, a campaign objective, set from the outset and assessed and reported at the end with other objectives, could be "to score either proud or extremely proud from all members of the PR team (anonymously, on a standard Likert scale survey response) in answer to the question are you proud of your activities throughout this campaign?" Creating such objectives forms the base of the pyramid on which the ethical campaign is built; revisiting and assessing the same objectives at campaign end forms the pinnacle. In the middle segment of the pyramid, each tactic used in the campaign could also be assessed using a virtue approach, by asking "Am I proud of what this tactic does and how it does it?"

Virtue ethics clearly has benefits for practitioners seeking ethical guidance, but may be inadequate alone. Harrison and Galloway (2005) noted that tests using external virtue referents, such as a "significant other," are "at odds with the idea of developing of virtues by pursuing the internal goods of a practice" (p.11). They suggest it is sufficient for PR practitioners to simply ask the "pride" question. Reliance on personal pride to guide decision making assumes, however, an already well-developed set of personal morals and beliefs in which pride in social responsibility takes priority over, for example, pride in moving up the corporate ladder or pride in attaining income to support financial obligations or family responsibilities. In an industry where pure advocacy is highly materially rewarded, and justified from many ethical standpoints, Harrison and Galloway's absolute trust in intrinsic personal virtue as likely to result in broader social "goods" seems optimistic. At the opposite end of the spectrum, Harman argued that "the empirical findings of psychologists show that character-based approaches to ethics are useless" (as cited in Levy, 2004, p. 108), and McElreath (1997) warned against an "egoistic view of ethics [that] invites moral anarchy because it subordinates the views of others while, at the same time, asserting that all sincere individuals are right" (p. 56).

Boynton's (2003) finding that PR practitioners' ethical reasoning falls into clearly differentiated categories is also relevant here; she classified decision makers as absolutists, debaters, loyalists, and avoiders. A debater's decision on an ethical issue may oppose an avoider's decision on the same matter, but both feel pride in acting virtuously according to their personal values. Kim and Choi (2003) likewise found that "age and personal ethical ideology (idealism and relativism) had significant effects on the ethical judgment of professional ethics" (p. 79). Practitioners' personal values 
may also differ from those of groups involved in or affected by their activities, for example, in international communication campaigns. Roth, Hunt, Stavropoulos, and Babik (1996) also noted sizeable differences in understanding "what counts as ethical practice" (p. 151) across cultures (cf. Davis, Johnson, \& Ohmer, 1998).

\section{Using virtue ethics alone to judge a campaign is therefore problematic.}

Using virtue ethics alone to judge a campaign is therefore problematic because individual or cultural values vary, and some people, particularly new students or even possibly new graduates, may not yet have strong personal values and may need clear external referents to develop them.

The "pyramid" approach produces a middle-ground position: allowing that virtue ethics has something to offer but not expecting it to provide a total solution. The pyramid's plural or "menu" approach enables different personalities to work together on a campaign by customizing a multivalent or multicultural ethical approach. For example, in a multicultural PR team, each practitioner can nominate an ethics objective that reflects his or her cultural ethical values. The team may not be successful in meeting all diverse objectives, but the tracking and evaluation of each objective will provide a clear indication of those values the overall campaign favored. The pyramid enables practitioners to question ethics from multiple standpoints but still controls overall ethical management by requiring practitioners to follow and integrate the particular ethics measures chosen.

\section{Deontological Ethics}

Derived from Kantian philosophy, deontology involves following a prescribed set of duties or obligations (e.g., religious rules such as "Thou shalt not lie"). A common deontological position in public relations is advocacy, the belief that provided practitioners' specific behaviors are ethical against an agreed standard such as a professional ethics code, they can ethically promote clients' self-interests above all other interests. This approach is usually associated with Bernays $(1928,1955)$, but has adherents today. Martinson (2004), for example, argued that "the public relations practitioner representing a particular political cause ... can ethically attempt to persuade outside publics of the 'correctness' of the viewpoint he/ she is espousing" (p. 3), provided he or she does not lie or mislead in the process. Deontology can be incorporated into a campaign's planning base 
by setting specific objectives such as "we will always tell the truth" or "we will adhere to the ethics code in everything we do" (in measurable form), and into its pinnacle by checking whether such objectives have actually been attained.

Deontological approaches are also useful in the campaign's communication phase to assess the ethics of messages and communication outputs. Methods may include focus group pretesting, to ascertain whether audiences think proposed messages meet specific deontological ethics criteria such as truthfulness; textual checks for sexist, racist, ageist, or other discriminatory language; rhetorical analyses to check whether texts and messages are primarily informative or persuasive. It is not possible to overview all such tools here, but it is likely practitioners already use some form of textual check, such as a proofreader or copyeditor, and could expand the scope of existing text-checks to encompass ethics. An independent copyeditor could be asked to check for compliance against an ethics code, checklist, or principle chosen from the many available. Possible choices may include TARES (truth, authenticity, respect, equity, social responsibility; Baker \& Martinson, 2001), ${ }^{1}$ Kidder's (1995) checklist (Baker, 1997), Sissela Bok's (1978) test for deceit (Barney \& Black, 1994), or the propaganda index (Tilley, 2004); there are many others.

Ethics codes are probably the most common deontological tool, although there is a growing trend to design them using "values rather than prohibitions" (Harrison, 2004, p. 3) — that is, virtue rather than deontology. Codes of all types undoubtedly provide important indicators of "reasonable" behavioral standards at any point in a PR campaign. An obvious (and therefore rarely explicitly stated or tested) objective is for each specific campaign activity at every stage to adhere fully to relevant professional codes. Harrison pointed out that application of ethics codes, "in particular their effectiveness and enforcement, has been ... problematic" with, for example, both Australian and New Zealand PR institutes having "difficulties enforcing codes and sanctions in recent times" (p. 3). He pointed out that code enforcement is usually reactive, with assessments of compliance made only in response to a complaint. The pyramid makes code enforcement proactive and ensures compliance assessment is intrinsic to each campaign.

While deontological approaches are useful because they clarify the limits of reasonable behavior by providing absolute prohibitions and directives for specific acts, their inflexibility can be problematic, for example in situations where unconditional truth telling conflicts with safety, privacy, or other values. McCoy (2004) gave the example of Greenpeace as an organization whose PR activities "have involved civil disobedience" (p. 109). A deontological judgment about Greenpeace as law breaker conflicts with one made using, for example, a utilitarian approach, in which actions are 
judged by their consequences, rather than some rightness inherent in the acts themselves.

Deontology's primarily tactical focus has also come under fire. Fitzpatrick and Gauthier (2001), for example, criticized advocacy's ethics, suggesting that, unlike the legal system where participants receive legal representation as a right, PR representation is not available to everyone, and audiences do not have equal skills to recognize and evaluate PR activity. Regardless of adherence to a code, a practitioner may therefore still be acting unethically in representing clients' interests. This approach is closer to a utilitarian ethics perspective, based on the principle that the ethical action is the one that leads to most happiness. Thus while codes (both professional ethics and corporate conduct policy and laws) are important referents throughout PR campaigning, and while they provide minimum guidelines as to what constitute socially accepted norms of "good character," alone they may be insufficient to navigate all possible ethical issues.

\section{Consequentialism}

Consequentialists judge actions by their outcomes. The best-known technique is utilitarianism, in which an assessment is made of who has been affected, and in what ways, and the right action is deemed to be that which creates maximum total benefit. One method for considering outcomes involves drawing a flow chart or mind map that shows all stakeholders, links each to all possible options for acting, then lists the likely consequences of each option for each stakeholder before finally choosing a strategy. This SOCS - stakeholders, options, consequences, strategymethod does not itself select "right" options but does help identify consequences before choosing actions. Another closely related test is the benefit-harm assessment, in which a calculation is made about whether the benefits to stakeholders outweigh the harm. Other possible tests of consequence are reversibility (Would you be happy for the outcome to affect you in the same way it has your public?), universalizability (consider the outcome if everyone behaved this way), and Rawls's (1971) original position in which the more ethical outcome is seen to be that in which prior deficits are taken into account in distribution of benefits. (For a helpful overview of Rawls and fellow utilitarian R. M. Hare, see Stewart, 1991.)

While consequentialist approaches are clearly crucial components of PR ethics, on their own they may obscure unethical means used to obtain a desired outcome. For example, a pure consequentialist would endorse a lie if it ultimately resulted in more happiness or more wide-spread benefit than truth telling. Tests such as SOCS or benefit-harm do not consider means. Consequentialism also has its own complexities: For example, what is hap- 
piness or benefit, who is entitled to determine it, and against what timeframe should judgements about advantage or detriment be made?

Thus each of the common approaches to PR ethics has benefits, yet each also has limitations. The ethics pyramid helps manage these limitations by encouraging a combined approach in which some virtue, some deontological, and some consequentialist tools are used within a single campaign.

\section{How to Use the Pyramid}

The ethics pyramid provides a practical framework that complements the theoretical approaches of much PR ethics literature. It is not a new ethics tool or alternative philosophical approach, but rather a new organizing strategy that enables practitioners to choose the ethics approaches that work for them from the many on offer, and integrate those chosen approaches into the actual daily business of designing, implementing, and evaluating a PR campaign. This article cannot assess every possible reasoning tool that could be fitted into the pyramid's holding and organizing structure, but has explored some of the more common ones that may already be familiar to practitioners. Individual organizations or practitioners must negotiate the way they want to use the pyramid and what methods work best for their particular activities and environment at each stage of a campaign. What is crucial is that some form of ethics consideration be built into each campaign phase. The following sections suggest some generic guidelines on how such incorporation could occur. The pyramid is followed from the base upwards.

\section{Stage 1: Ethical Intent}

To use the ethics pyramid, practitioners first need to make their own generic menu of the ethics tools they like to use. Although the variety of ethics approaches on offer can seem intimidating, this need not be a daunting task. Practitioners can start with a very basic list and add new methods or approaches over time if they have opportunities to learn other methods. Even three simple tools (e.g., discuss ethics with colleagues to establish what makes us proud, adhere to ethics code in all actions, and ensure all outcomes are ones I would be happy to have reversed and applied to me) are sufficient to create a pyramid with measurable objectives. Table 1 gives a detailed menu, but a much shorter one is also adequate.

For each campaign, practitioners should (in consultation with colleagues, clients, and stakeholders, where possible) choose several appro- 
Table 1. Ethics Tools

Virtue

Deontology

Consequentialist Mixed mode
Aristotle's mean, ethics brainstorm, ethical reflection session, mum test, publicity test, pride test

Laws, codes (conduct, professional ethics), checklists (e.g., Kidder, propaganda index), prohibitions (Bok)

Universalisability, reversibility, benefit/harm, SOCS, Rawls

TARES, Potter Box

Note. SOCS = stakeholders, options, consequences, strategy; TARES = truth, authenticity, respect, equity, social resposibility.

priate ethics tools from their menu, and use them to customize a range of ethical objectives. Ideally, given the complementary nature of different ethics approaches outlined previously, objectives should span the main approaches; in other words, practitioners should set some ethical objectives that outline what virtues they want their campaigning behavior to embody, some that identify rules or duties they wish to follow, and some that outline what ethical outcomes they wish to achieve.

As with any set of objectives, some should be strategic for the campaign's ethics as a whole, and some should be tactical, prescribing the ethics of specific devices that will be used. Practitioners also need to decide at this stage how, and by whom, each objective will be measured, and this should be clear in their wording (numerous articles about objective writing available in both the strategic planning and public relations literature can assist with this step).

As with any other setting of objectives, formative research will be required to establish benchmarks. Practitioners will need answers to questions such as "How do clients currently perceive the ethical performance of your consultancy?" and "How do stakeholders currently perceive the ethics of the client organization?" if they wish to measure improvement in these areas. Once these and similar ethics-related research questions are built into regular benchmarking research, performance against them will be relatively easy to track.

In summary, at Stage 1, objectives should be set that reflect a stakeholder-client-practitioner consensus on the ethical virtues, rules, and outcomes required in this campaign. In practical terms, this may involve such steps as building ethics questions into all precampaign attitudinal research to ascertain target audience ethical expectations, holding ethics discussions with clients to clarify their ethical expectations and to reach a practitioner-client consensus on appropriate objectives, and writing ethics into PR team meeting agendas. As an absolute minimum, Stage 1 would always require practitioners to write very clear personal objectives for their own ethical behavior. 


\section{Stage 2: Ethical Means}

The second phase of ethical campaign building occurs at the communicating stage. Here, the tools proposed for use in the campaign (a speech, media release, advertisement, brochure, event, or any other tactic) should be individually assessed for ethical characteristics at the same time as they are assessed for other attributes such as readability, correct grammar, cost per view, or key message exposure. Methods may include textual checking or focus-group pretesting. Any objectives from Stage 1 that relate to specific tactics should be assessed here before the campaign is launched, and tactics should be adjusted until they meet the ethical requirements outlined. Identifying and resolving tactical ethical issues using prelaunch testing is potentially money saving, as it could save an embarrassing recall. Again, this type of pretesting is a standard activity in most campaigning and can simply be extended to incorporate specific ethics considerations.

\section{Stage 3: Ethical Outcomes}

The final stage in the ethical campaign involves testing overall ethical performance by evaluating the strategic ethics objectives set in Stage 1. When these objectives have been properly designed in the first instance, with clear measurements, specific evaluation methods, and baseline data, this is a relatively simple process of replicating the formative research, comparing the pre- and postcampaign data, and reporting the results in campaign summary documents, along with any recommendations for future adjustments to ethical compliance policy.

The pyramid in Figure 1 gives a generic example of the tasks required to implement ethics measurement. Each task can then be personalized (as in Figure 2) to reflect individual or cultural values, or addressed in multiple ways to reflect the diverse values of team or international environments. Each team member can nominate a technique that reflects his or her values, and transform it into a specific campaign objective. For example, a practitioner may wish to adopt a feminist ethic of care in their work (Hill, Glaser, \& Harden, 1998). By working such an ethic into the campaign schedule using the ethics pyramid, practitioners can ensure their ethos of care involves not only good intentions but also accountable means and ends. Conversely, if practitioners find a particular ethics procedure unhelpful at any particular stage or for any particular campaign, it can be exchanged for another technique without discarding the overall pyramid, and therefore without "giving up" on ethics as a whole because of a microfailure. The key principle is not which ethical approaches are chosen, but rather transformation of ethics from intangible background requirement to tangible 


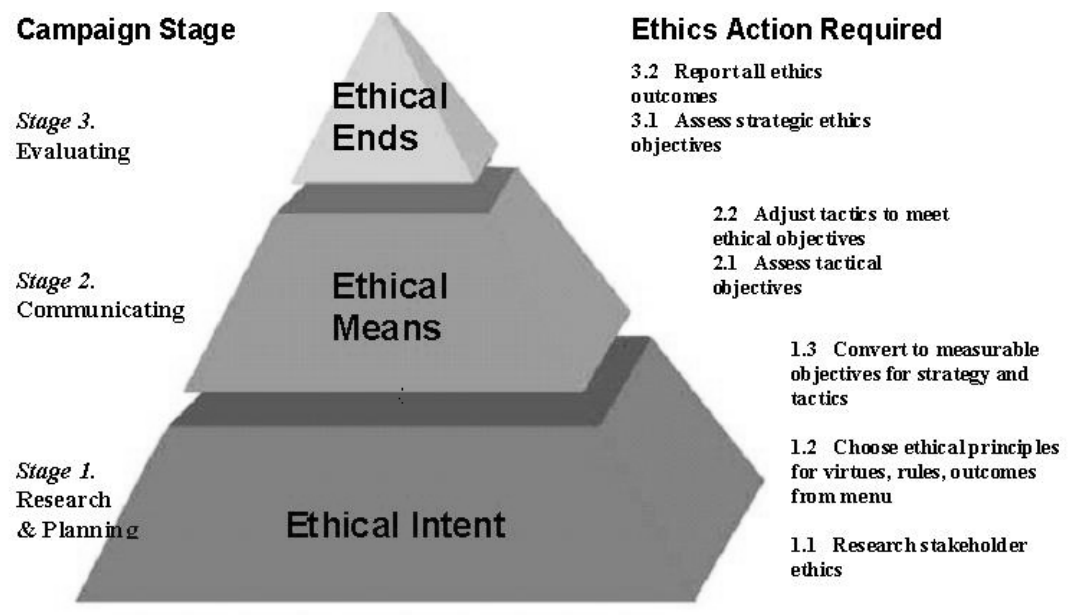

Figure 1 The generic pyramid. Illustration by M. A. Smith, 2005, with acknowledgment to Macnamara (2002).

\section{Campaign Stage}

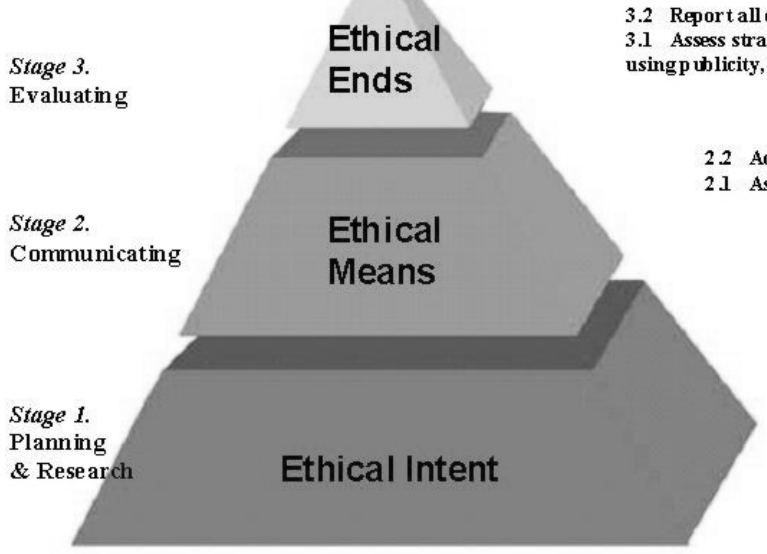

\section{Ethics Action Required}

3.1 Assess strategic ethics ob jectives using p ulicity, code, \& R awls' tests
2.2 Adjust tac tics to meet T ARES

1 Assess tac tic al objectives using T ARES
13 Devise measures for princ ples for strategy and tactics

1.2 Agree princip les

Vir tues: publicity test will guide all behaviour

Rules: all actions will meet client c orporate cond uct code and PR ethics code, all tac tics willpass T ARES test Outc omes. Raw ls

1.1 E thics benchmark questions in survey \& focus grou research, ethics brainstorm $w$ ith team and client

Figure 2 A sample customized pyramid. Illustration by M. A. Smith, 2005, with acknowledgment to Macnamara (2002). 
items in the campaign schedule. Figure 2 shows one possible customization of the pyramid.

\section{Proactive Pyramid}

The ethics pyramid improves ethical standards of PR practice because it incorporates proactive ethical reasoning into every step of the PR process, rather than leaving ethics in the background until specific "ethical dilemmas" or "problems" arise or are recognized. Galloway (2004) argued that there are inbuilt deficiencies with a "problem-solution-next problem" PR model in which "practitioners see themselves, and are seen by others, as professional communication, reputation, and issues problem-solvers" (p. 1). He argued that a problem-solving approach "often delivers short-term results that produce yet another round of dilemmas to be dealt with" (p. 1), recommending appreciative inquiry as offering a more "constructive vocabulary which will help build a 'virtuous cycle' of positive expectations and organisation-enhancing behaviours" (p. 3). Galloway's argument also makes sense for the specific area of ethical behavior and ethics assessment in campaigns. The ethics pyramid takes ethics forward because it makes ethical compliance a positive, aspirational component of PR rather than a punitive or "problem-based" area addressed only when an ethical dilemma arises.

Used consistently, the ethics pyramid, like appreciative inquiry, "rationalises and reinforces the habit of mind that moves through the world in a generative frame, seeking and finding images of the possible rather than scenes of disaster and despair" (Watkins \& Cooperrider, 2000, p. 1, as cited in Galloway, 2004, p. 3). By aiming high, setting and evaluating positive ethical objectives, and checking back against benchmarks, practitioners can rank their ethical achievements and track ethical progress over time. Formalizing ethics as part of campaign measurement enables practitioners to illustrate some tangible benefits from time spent talking and thinking about ethical issues, by linking ethics measurement to practitioner, consultancy, and client reputation. Such data can support the profession's efforts to address its poor reputation on ethical matters.

\section{Conclusions}

The ethics pyramid is a framework for ethical planning and evaluation designed specifically to integrate with existing activity in public relations campaigns. It has several benefits: It encourages practitioners to use multi- 
ple ethics approaches throughout campaign activity by providing a menu of choices for ethical guidance; it integrates ethics at each existing stage of a standard PR campaign structure, following the typical management-byobjectives approach so that setting ethics objectives at the outset makes subsequent checks of ethical outcomes an integral part of campaign evaluation; it provides a simple graphic representation of "ways to think about ethics" that can be carried in a pocket and consulted at a glance; it is adaptable to a range of cultures and intercultural situations where individual values may differ; and it makes ethics as concrete as possible, with measurable and reportable outcomes.

Harrison (2004) argued that the challenge for PR "is to move beyond an approach to ethics education and training which simply says, 'here's the code of ethics, now follow it'; to an approach that genuinely fosters habits of good character in practitioners" (p. 6). The ethics pyramid, with its tangible integration of ethical intent, ethical means, and ethical ends into daily campaign activity, goes some way toward achieving that aim.

\section{Note}

1. Like the pyramid, TARES is a multimethod system that can be used to assess campaigns as a whole, but I personally find it easier to use for individual outputs because its steps do not readily correspond to the standard stages of campaigning, and it does not suggest ways to measure its specific components in the overall campaign context. As a check of individual outputs, however, I find it invaluable. TARES can be incorporated into the pyramid's measuring system by creating, at Stage 1, an objective for all campaign collateral to pass the TARES test (and specifying who will judge-client, practitioner, audience test group, or all three-and how they will judge, e.g. scaled survey response), and adjusting each output at Stage 2 until it meets the test in the required way.

\section{References}

Baker, S. (1997). Applying Kidder's ethical decision-making checklist to media ethics. Journal of Mass Media Ethics, 12, 197-210.

Baker, S. (2002). The theoretical ground for public relations practice and ethics: A Koehnian analysis. Journal of Business Ethics, 35, 191-205.

Baker, S., \& Martinson, D. L. (2001). The TARES test: Five principles for ethical persuasion. Journal of Mass Media Ethics, 16, 148-175.

Barney, R. D., \& Black, J. (1994). Ethics and professional persuasive communications. Public Relations Review, 20, 233-248.

Bernays, E. L. (1928). Propaganda. New York: Liveright.

Bernays, E. L. (1955). The engineering of consent. Norman: University of Oklahoma Press.

Bok, S. (1978). Lying: Moral choice in public and private life. New York: Random House. 
Bowen, S. A. (2004). Expansion of ethics as the tenth generic principle of public relations excellence: A Kantian theory and model for managing ethical issues. Journal of Public Relations Research, 16, 65-92.

Boynton, L. (2003, July/August). The gray areas of ethical decision-making: The emergence of an ethical action continuum among public relations practitioners. Paper presented to the Public Relations Division for the Association for Education in Journalism and Mass Communication annual conference, Kansas City, MO. Retrieved February 2, 2005, from http:/ / list.msu.edu/cgi-bin/wa?A2=ind0309d\& $\mathrm{L}=$ aejmc $\& \mathrm{~F}=\& \mathrm{~S}=\& \mathrm{P}=17191$

Cancel, A. E., Mitrook, M. A., \& Cameron, G. T. (1999). Testing the contingency theory of accommodation in public relations. Public Relations Review, 25, 171-198.

Childers Hon, L. (1998). Demonstrating effectiveness in public relations: Goals, objectives, and evaluation. Journal of Public Relations Research, 10, 103-135.

Davis, M. A., Johnson, N. B., \& Ohmer, D. G., (1998). Issue-contingent effects on ethical decision making-A cross-cultural comparison. Journal of Business Ethics, 17, 373-389.

Dozier, D. M. (1984). Program evaluation and the roles of practitioners. Public Relations Review, 10(2), 13-21.

Fitzpatrick, K., \& Gauthier, C. (2001) Toward a professional responsibility theory of public relations ethics. Journal of Mass Media Ethics, 16, 193-212.

Fleisher, C. S., \& Mahaffy, D. (1997). A balanced scorecard approach to public relations management assessment. Public Relations Review, 23, 117-142.

Galloway, C. (2004). Appreciative public relations: An alternative to the problemsolution loop. PRism 2. Retrieved August 30, 2004, from http:// praxis.massey.ac.nz/fileadmin/Praxis/Files/Journal_Files/Issue2/Commentary/Galloway.pdf

Grunig, J. (2001). Two-way symmetrical public relations: Past, present, and future. In R. Heath \& G. Vasquez (Eds.), Handbook of public relations (pp. 11-30). Thousand Oaks, CA: Sage.

Grunig, J., \& Grunig, L. (2001). Guidelines for formative and evaluative research in public affairs: A report for the department of energy office of science. College Park: University of Maryland Department of Communication. Retrieved November 12, 2001, from http:/ / www.instituteforpr.com/printables

Harrison, J. (2004). Conflicts of duty and the virtues of Aristotle in public relations ethics: Continuing the conversation commenced by Monica Walle. PRism 2. Retrieved September 2, 2004, from http:/ / praxis.massey.ac.nz/fileadmin/Praxis / Files/Journal_Files/Issue2/Harrison.pdf

Harrison, K., \& Galloway, C. (2005). PR ethics: A simpler (but not simplistic) approach to the complexities. Prism 3(1). Available at http:/ / praxis.massey.ac.nz/ fileadmin/praxis/files/journal_files/issue3/harrison_galloway.pdf

Hill, M., Glaser, K., \& Harden, J. (1998). A feminist model for ethical decision making. Women and Therapy, 21, 101-121.

Kidder, R. (1995). How good people make tough choices. New York: Simon \& Schuster/ Fireside.

Kim, Y. W., \& Choi, Y. J. (2003). Ethical standards appear to change with age and ideology: A survey of practitioners. Public Relations Review, 29, 79-89. 
Leeper, K. A. (1996). Public relations ethics and communitarianism: A preliminary investigation. Public Relations Review, 22, 163-179.

Leeper, R. V. (1996). Moral objectivity, Jurgen Habermas's discourse ethics, and public relations. Public Relations Review, 22, 133-150.

Levy, N. (2004). Good character: Too little, too late. Journal of Mass Media Ethics, 19, 108-118.

Macnamara, J. (2002). PR metrics: Research for planning and evaluation of PR and corporate communication. Chippendale, New South Wales: MASS Communication Group. Retrieved August 31, 2004, from http:/ /www.masscom.com.au/ Downloads/PR\%20Metrics\%20(A4).pdf

Marsh, C. W. (2001). Public relations ethics: Contrasting models from the rhetorics of Plato, Aristotle, and Isocrates. Journal of Mass Media Ethics, 16, 78-98.

Martinson, D. L. (2000). Ethical decision making in public relations: What would Aristotle say? Public Relations Quarterly, 45(3), 18-21.

Martinson, D. L. (2004). An essential component in teaching public relations ethics. TPR: Teaching Public Relations, 64. Retrieved September 4, 2004, from http:/ / lamar.colostate.edu/ aejmcpr/64martinson.pdf

McCoy, L. (2004). Ethical practice. In J. Johnston \& C. Zawawi (Eds.), Public relations: Theory and practice (2nd ed., pp. 104-133). Crows Nest, New South Wales: Allen \& Unwin.

McElreath, M. (1997). Managing strategic and ethical public relations campaigns (2nd ed.). Dubuque, IA: Brown \& Benchmark.

Pearson, R. (1989). Albert J. Sullivan's theory of public relations ethics. Public Relations Review, 15(2), 52-62.

Rawls, J. (1971). A theory of justice. Cambridge, MA: Belknap/Harvard University Press.

Roth, N. L., Hunt, T., Stavropoulos, M., \& Babik, K. (1996). Can't we all just get along: Cultural variables in codes of ethics. Public Relations Review, 22, 151-161.

Stewart, D. (1991). Theoretical foundations of ethics in public administration: Approaches to understanding moral action. Administration \& Society, 23(1), 357-373.

Tilley, E. (2004). Propaganda-Who, us? John Howard's "letter to fellow Australians" in the Australian Government terrorism kit. Media International Australia, $113,30-43$. 